\title{
ПЛОДОТВОРНЫЙ СМЕХ ФИЛОСОФА, ИЛИ О ПРИНЦИПАХ КИТАЙСКОЙ КЛАССИФИКАЦИИ
}

\begin{abstract}
Е.А. Лебедь
Несомненно, что китайская и западноевропейская традиции по своим парадигматическим - экзистенциальным, ментальным, символическим, смысловым, языковым - основаниям жестким образом конфликтуют друг с другом: в их базовых установках заложено противоречие основных онтологических представлений (манифестационизм креационизм). Они абсолютно несводимы друг к другу, неконвертируемы, взаимоисключаемы. Это противоречие начинает проявляться уже на уровне языка как сложной семиотической и коммуникативной системы.

Цель настоящей работы - выявить основные критерии классификации, пронизывающей (и во многом формирующей) все сферы культуры, а потому занимающей в китайской традиции весьма почетное место. Сделаны экскурсы в западноевропейскую философию, чтобы более выпукло показать специфику китайских классификационных систем.

Ролан Барт, всю свою жизнь воплощавший программу противостояния и подрыва принципа власти как такового, власти всегда агрессивной идеологии, натурализующейся в культуре, власти мифов мелкобуржуазного сознания, показал, что язык является не невинным проявлением коммуникации, а обязательным выражением неумолимо констатирующей власти. До Барта принудительный характер языка был опознан Ф. Шлейермахером, Ф. Боасом, Р. Якобсоном. Уже в наше время С. Жижек, не претендуя на новаторство, выделил фундаментальную форму насилия, таящуюся непосредственно в языке и насаждаемую его смысловой вселенной, назвав ее символическим
\end{abstract}


насилием. Символическое насилие, вероятно, наименее зримо, но и наиболее объективно в отличие от «субъективного» насилия, совершаемого какой-либо хорошо опознаваемой силой $[4$, с. 5-6].

«Тема языка» звучит не только настойчиво и контрапунктурно, но как агрессивно детерминирующая сила. Для иллюстрации этого «положения дел» можно сослаться на диалог П. Валери и А. Жида, состоявшийся, как передает А. Моруа, в 1934 г. и перекликающийся с не менее эпохальным «разговором из двух углов» о принуждающей сущности культуры между Вяч. Ивановым и М. Гершензоном. ЖКид: «Если бы мне не давали писать, я бы покончил с собой». Валери: «А я покончил бы с собой, если бы меня заставляли писать» [3, с.608]. Р. Барт в актовой лекции, прочитанной в Коллеж де Франс 7 января 1978 г., снова констатирует: «язык не реакционен и не прогрессивен; это обыкновенный фашист, ибо сущность фашизма не в том, чтобы запрещать, а в том, чтобы понуждать говорить нечто» [1, с. 549]. Почему мы не замечаем таящейся в языке власти? Потому что забываем, как справедливо считает Барт, что язык как общеобязательная форма принуждения - это средство классификачии, а всякая классификация («стадная тяга к повторению») есть способ подавления [1, с. 548].

В традиционном Китае господствовали совсем иные принципы. Проницательный Х.Л. Борхес уловил эту специфику, в утонченном эссе «Аналитический язык Джона Уилкинса» придумав (якобы обнаружив ее у синолога Франца Куна) классификацию из некой китайской энциклопедии «Небесная империя благодетельных знаний». В этой сумбурной энциклопедии животные делятся на: а) принадлежащих Императору, б) набальзамированных, в) прирученных, г) сосунков, д) сирен, е) сказочных, ж) отдельных собак, з) включенных в эту классификацию, и) бегающих, как сумасшедшие, к) бесчисленных, л) нарисованных тонкой кистью из верблюжьей шерсти, м) прочих, н) разбивших цветочную вазу, о) похожих издали на мух [2, с. 218].

Симптоматично, что книга М. Фуко «Слова и вещи. Археология гуманитарных наук» вызвана к жизни именно «Аналитическим языком» Борхеса: этим признанием начинается предисловие к ней. «Точнее, говорит Фуко, - смехом, прозвучавшим под влиянием его чтения, смехом, который колеблет все привычки нашего мышления - нашего по эпохе и географии - и сотрясает все координаты и плоскости, упорядочивающие для нас великое разнообразие существ, вследствие чего утрачивается устойчивость и надежность нашего тысячелетнего опыта Тождественного и Иного» [12, с. 28].

Фуко, кроме прочего, прав в том, что устойчивость, надежность, 
рациональный порядок нашего мышления и нашего восприятия реальности этой классификацией подвергаются своего рода испытанию на прочность, и мы убеждаемся, что порядок, питаемый многовековой привычкой, не абсолютен, незыблемость его весьма условна. Привычно-уютный и не единственно возможный порядок против «беспорядка неуместного», порожденного «сближением несовместимого» и всеобщей со-общительности: «может быть, я завишу от чешуйки на хребте змеи или от крылышек цикады?» [11, с. 73]. Кто знает? Как у мага XVI в. Джованни Батиста делла Порта: сосновую смолу и звезду Бетельгейзе связывает прочная дружба. Нам совершенно непонятно, каким образом можно связать космический объект и живицу, поэтому мы квалифицируем подобные сближения как ненаучную фантастику, балагурство и магию в лучшем случае, или дичайший бред - в худшем (впрочем, оценки могут легко меняться местами).

Сейчас я хочу задать вопрос: смеяться ли нам подобно Фуко, читая Линнея, или почтительно склонить голову перед гением научного каталогизаторства, проявившегося, в том числе и в создании грандиозной системы (см.: [6])«априорных пород ученых ботаников», которые суть «научное поголовье», как неприлично выразился один из современных философов? Нечего и говорить, что попытка объяснить мир живых существ с помощью механических законов, применимых к неорганическому миру, методом разлагающего анализа, терпит фиаско уже на старте, так сказать онтологически, но до сих пор продолжает свое победное шествие как исследовательская программа sui generis. Я имею в виду сугубо механическую «точку зрения блохи», перепрыгивающей с рода на вид и с вида на род (Р. Штейнер). Если продолжить энтомологическую метафору, то, как говорил Гераклит, - это подобно ловле вшей (=накоплению эмпирических фактов): чем больше увидел и поймал, тем меньше осталось. Между знаком (сема по-гречески ведь не только знак, но и могильная плита, подобно телу скрывающая, погребенную под ней душу) и сущностью обнаруживается непреодолимый провал, а живое существо превращается в объект, т.е. «противопоставленный», «оставленный на произвол», «являющийся жертвой»: словом убивают живую вещь.

Классификацию ботаников у Линнея можно счесть за курьез, а можно за... образец научной системы. Линней, которого называли вторым Адамом, присваивающим живым существам имена, со своей врожденной классификаторской страстью подчиняет жесткой номенклатурной дисциплине все «поголовье ботаников», отодвинув растения в дальний угол, где сама жизнь, как оказалось, отсутствует. Смеяться 
ли нам вместе с Фуко, который писал об этом удивительном времени:

естественная история в классическую эпоху не может конституироваться в качестве биологии. Действительно, до конца XVIII века жизнь как таковая не существует. Существуют только живые существа. Они образуют один или, скорее, несколько классов в ряду всех вещей мира: и если можно говорить о жизни, то лишь исключительно как о каком-то признаке - в таксономическом смысле слова - в универсальном распределении существ [12, с. 190].

Конечно же, в данном случае смех Фуко нас интересует менее всего. На самом деле все, несмотря на причудливость, достаточно серьезно, в чем я и попытаюсь убедить читателя: нас интересует сам принцип китайской классификации. Смех, имплицитно звучащий в предисловии Фуко, может свидетельствовать: (1) об иронии Борхеса, граничащей с юмором, чего мы отрицать не станем, и/или (2) о пределе нашего мышления - то есть совершенной невозможности мыслить таким образом. Предел нашего мышления в несоответствии интеллектуальных паттернов, питающих две культуры-западноевропейскую и китайскую. В итоге: наше восприятие упирается в (Великую Китайскую) стену, выстроенную нашей привычкой мыслить в координатах, жестко заданных всей нашей культурной традицией. Один венский музыкант, вероятно прослывший неисправимым чудаком, не допускал детей в свою музыкальную школу, если они уже научились читать и писать: грамотные дети безнадежны в обучении музыке. Умение читать и писать (как тут не вспомнить ученых невежд-китайских Прокрустов, готовых «вытягивать ноги уткам и отрубать ноги журавлям», которых зло высмеивал Чжуан-цзы), используя исключительно коды европейской культуры, часто не позволяет адекватно воспринять парадигмы иной культуры.

По точному замечанию Сыма Цяня, «классифицировав, можно познать». В традиционном Китае одни и те же классификационные схемы символически распространялись на все сферы культуры и науки: мифологию, религию, философию, хронографию, историю, космологию, космогонию, космографию, географию, астрономию, астрологию, математику, химию, алхимию, медицину, психологию, литературу, музыку, театр, архитектуру, изобразительные и боевые искусства, политику, деньги, одежду, кулинарию, домоводство и т.д. Иными словами, символ в китайском универсальном классификационизме является представителем потенциально бесконечного ряда различных сущностей, относящихся ко всем слоям и сферам бытия [5, с. 36]. Ведь в традиционной китайской философии считалось, что именно симво- 
лы, а не слова или тексты способны исчерпывающе выражать высшие идеи. Через безмолвие символа, обнажаемое словом, выражается вся глубина просветленного сознания и сокровенный лик реальности. У современного европейца может вызвать удивление способность китайцев, которые, «презрев логику», могли классифицировать, при этом добиваясь достаточной познавательной оформленности. Ведь для них все классы вещей и явлений по существу связаны друг с другом, если они по духу - по тонам гун и изюэ-одинаковы [7, с. 183]. Следует заметить, что ни одна из даосских классификационных схем не претендовала на универсальность, но все они апеллировали к мировому порядку универсальных законов сознания и природы: даос «скитается вместе с духовной силой Неба и Земли».

Поэтому, снова возвратимся к Фуко, наш взор восхищен этой непривычной («безумной») таксономией. Очарование иного способа мыслить, предстоящего нам, он называет экзотическим. Борхес, этот неутомимый мистификатор, любитель вымысливать несуществующие существа, несуществующие (в нашем простодушно-унылом мире «формализованного знания», разлагающего анализа, якобы «правдивых историй», чуждом сладкому страху, метафизической опасности и радостной близости к зиянию бытия) обстоятельств, изобретатель запутанных и безвыходных ситуаций, в одном небольшом тексте (иронично!) выговорил базовые принципы китайского мировосприятия, а именно: полиморфность, суперпозиционность и многоаспектность. Этот мир можно назвать миром рядоположенных объектов, миром насквозь магическим, и, в отличие от причинного мира Запада, коррелятивным. Отсюда и символизм китайской культуры (вэй- «космического узорочья»), формировавшийся на основе иероглифического полисемантизма и классификационизма и категориально-ассоциативного мышления. «Сердце соответствует финику, печень соответствует вязу. Я пронизываю Небо и Землю, в сумрачном сне обнаруживаю воду, в ясном сне обнаруживаю огонь. Небо и Земля пронизывают меня. Я и Небо и Земля вроде бы едины, а вроде бы и раздельны, в смутности и неясности каждое возвращается к себе» (даосский трактат «Гуань Инь-цзы») [9, с.220]. В этом мире все сущее, представляющее собой лишь различные формы и состояния духовно-квазиматериальной витально-энергийной субстанции мира ци, постоянно переплавляется, меняя свои очертания:

Можно Небо и Землю

с пьлающим горном сравнить. 
Превращения и перемень

Уголь - сильи инь-ян,

свершают работу,

все на свете - кипящая медъ.

То погаснет, то вновъ разгорится огонь, переплавкам вселенским нет счета,

Не найти постоянства ни в чем.

Мириадь метаморфоз,

сотни, тысячи превращений,

Нет предела-кониа непрестанному

круговороту.

Так писал Цзя И, великий поэт и философ (200-168 гг. до н.э.) в «Оде зловещей птице» («Фу няо фу»), где «Небо и Земля» уподобляются плавильной печи, в которой непрестанно и вечно переплавляются вещи, а пневма (uи) инъ и пневма ян служат углем. В пределе своего бытия пневма совпадает с Великой Пустотой (тай сюй) как пространственно-временной безграничностью и воплощает собой неисчерпаемое разнообразие «Хаоса»-нерасчлененного единства, Хунь дунъ. Благодаря континуальности и динамичности, ии связана с психоэмоциональной сферой. Мудрец не благоволит ни одной из противоположных тенденций, поэтому его ии сохраняется в целостности: слушать не ушами, а сердцем, не сердцем, а духовными токами, т.е. посредством ци внимать внутреннему в себе, и, воздействуя духовной силой, соединяться со всей тьмой существ, 一 говорится в «Чжуан-цзы» $[11$, c. 80,120$]$.

Поэтому традиционный китайский мир энергиен, а не спиритуален или материален, динамичен, а не статичен благодаря динамичности жизненной силы ци, пронизывающей весь Универсум. Мир процессуален, а не веществен в том смысле, что каждая вещь (как и вся тьма вещей) - тоже процесс [9, с. 11]. Действительность при таком мировосприятии представляется как «множество континуальных масс» (А.И. Кобзев).

А.Н. Уайтхед, создатель «философии организма» и «философии процесса», считал прояснение значения Гераклитовой фразы «все вещи изменяются» главной задачей метафизики, вся проблематика которой основана на антитетике философии субстанции и философии становления. Среди предшественников философии процесса Уайтхед называет древнееврейского Псалмопевца, Гераклита и поэзию «на всех стадиях цивилизации» [10, с. 293-294]. К китайской мысли философ, 
как свидетельствуют его тексты, не обращался. И это несмотря на то, что процессуальность была для даосской традиции одной из важнейших философских интенций. Например, в «Чжуан-цзы» звучит вполне гераклитовская тема становления: «Ведь вы, сидящий ныне передо мной, не тот, кто сидел здесь прежде» [11, с. 64]-сознающее $Я$ входит в поток ощущений. Для даосов же становление - суть (само)превращение духа и вещей, неизменная изменчивость, а феноменальная реальность не обладает онтологическим единством (сказать «все едино», значит отделить себя от всеобъемлющего единства) или принципом, управляющим явлениями. «Чем больше вещи отличаются друг от друга по своему облику, тем более они подобны в том, что существуют сами по себе» (Го Сян) (цит. по: [11, с. 408]).

Если в авраамических религиях и в махаяне (буддизм) самой своей быстротечностью и непостоянством мир указывает на нечто, лежащее вне его пределов, на некую трансценденцию, то китайский (или, скорее, даосско-конфуцианский, если рассматривать его доктринальнофилософски как имеющий общую культурную основу и общую идейную мотивировку) мир един и неделим, насквозь имманентен. Это, по точному выражению синолога Норманна Жирардо, мир хаотического порядка и благого беспорядка. Но радикальная имманентность мира по даосским представлениям невозможна без столь же радикальной трансцендентности сугубо безличного универсального Пути Дао. Дао парадоксальным для нас образом столь же трансцендентно, сколь и имманентно, между Небом и человеком зазора нет. Именно в этом стремлении осмысливать реальность в двух измерениях и коренится, по мнению исследователей китайской традиции, начало философии.

В этом мире грани между сном и бодрствованием (вспомним притчу Чжуан-цзы о счастливой бабочке), жизнью и смертью (они суть метаморфозы сущего и они - судьба), красотой и безобразием (весь чувственный мир, как единый организм, сакрален, поэтому он - благо), живым и косным, материей и сознанием (дух натурален, природа одухотворена) просто не существует.

Какие отношения, например, между желтым цветом, землей, числом пять, центром, низом, а также (добавим к базовым пяти еще два элемента) юбкой и счастьем может усмотреть европеец, мыслящий в рамках принципа причинности как формы всеобщей связи явлений? Что объединяет члены этого классификационного ряда? В умозрении традиционного Китая одной из основополагающих категорий была категория у син («пять элементов», «пять стихий», «пять действий» или 
«пять фаз», но не «пять субстанций», что было бы более понятно для европейского мышления, зачарованного Аристотелевыми «Категориями» с их субстанцией, сущностью, усией), наиболее детально разработанная в лоне натурфилософской школы инъ-ян изя. Категория $y$ син обозначала универсальную классификационную схему, согласно которой все основные параметры мироздания - пространственно-временные и двигательно-эволюционные - имеют пятичленную структуру (подробнее см.: [5, с. 228-338]). Вероятно, это связано с преобладанием в древнем Китае пятеричного счисления (как это было, к примеру, в классификациях алгонкин, виннебаго и других племен сиу, исследованных П. Радином еще в первой половине XX в.). Китайские стихии суть некие первопринципы, посредством резонирования с которыми организуются вещи «того же рода». Принцип же резонирования был заимствован из музыкальной практики, начало которой положила Нюйва - полуженщина-полузмей, архаическое божество, подарившее людям, как известно, шэнхуан - губные органчики из бамбуковых трубок, воткнутых в тыкву-горлянку.

Весь приведенный выше ряд объединяет принадлежность всех его членов к символу (элементу, фазе, стихии) космогонического порядка «земля» («почва»). ЖКелтый цвет - цвет Земли, гамма красок в древнем Китае состояла из пяти элементов, и желтый в ней занимал иентральное место, положение Земли по отношению к Небу низшее, что символизировано нижней частью китайской традиционной одеждыюбкой. Но причем здесь счастье? Один из афоризмов чжоуской «Книги Перемен» гласит:

Слабая черта на пятом месте.

Желтая юбка.

Изначальное счастье [13, с. 267].

Этот пример показателен тем, что в классификационном ordo coприсутствуют несводимые (для нашего изощренного рацио) в отдельную систему цвет, стихия (или нижняя часть биполярного универсу-

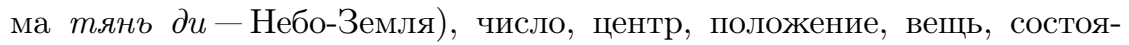
ние - «чудесные встречи» несоизмеримых сущностей в безграничной со-бытийности Великой Пустоты - Матери мира, рождающей и носящей в себе все сущее и все возможные смыслы.

\section{$* * *$}

Индивидуальное, единичное, чувственно достоверное животное, растение, гриб, инфузория не интересны биологу (как и частный, пои- 
менный человек - философу), для него их просто нет. Потому что только подведение восприятия любого существа под понятие этого существа дает нам возможность познать его: «простая совокупность многих „здесь“, т.е. нечто всеобщее», как говорил Гегель. Это и есть западная логика себетождественности рода. По-иному: общее (итойность) рационально, индивидуальное $($ этость) - иррационально. Для даоса чтойность вещи - ничто, она для него иррелевантна. Его интересует, чем вещь может стать в своей временной текучести, в постоянном движении к непрерывному обновлению, а сознание - в движении за собственные пределы. В этом случае будет работать другое восприятие и другая логика - если угодно, поэзия, или то, что мы называем мистикой, которые по своей сущности враждебны строгой позитивной науке. Хотя, если быть точным, даосы пребывали вне дихотомии рациональное - иррациональное, общее - индивидуальное, поскольку Дао есть принцип самопревращения духа, где «внутренняя правда каждого человека неотделима от чистой сообщительности всех людей» $[9$, с. 5].

Китайские классификации я склонен рассматривать, в том числе, и как ансамбли неких семиологических структур, позволяющих нам ускользнуть за пределы сетки сублимирующего оправдания групповых интересов и прорваться, как сказал бы Р. Барт, «в новый и совершенный адамов мир», где слова еще не разучились передавать смысл самих вещей и не нуждаются в обретении первозданной свежести, наслаждения и счастья. Где слова вызывают не «тихую скуку порядка» (В. Беньямин), а... безмолвный смех философа, выводящий в сверхъязыковую реальность близости к бытию, в реальность бесконечной перспективы самоосуществления, стимулируя наше участие в этой (мета)реальности.

Полагаю, Борхес был очень далек от того чувства, которое можно было бы усмотреть в речах какого-нибудь, скорее современного, нежели древнего классификатора, в отчаянии повторяющего слова, скажем, Юма о проделках ребячливого, второразрядного или дряхлого Бога, бросившего на полпути свой примитивный эскиз. Далек, потому что «не существует классификации мира, которая бы не была произвольной и проблематичной. Причина весьма проста: мы не знаем, что такое мир» $[2$, с. 219]. А это, мне думается, и есть непременное условие для полноценного творчества, где прошлого «уже нет», а будущего «еще нет», прорастающего из изумления перед этим изменяющимся в причудливой игре и во многом непонятном мире. 


\section{Литература}

[1] Барт Р. Избранные работы: Семиотика: Поэтика. - М. : Прогресс, 1989. - C. 545-569.

[2] Борхес Х.Л. Аналитический язык Джона Уилкинса // Проза разных лет: Сборник. - М. : Радуга, 1989. - С. 216-219.

[3] Валери П. Об искусстве. - М. : Искусство, 1976.

[4] Жижек C. О насилии. - М. : Европа, 2010.

[5] Кобзев А.И. Учение о символах и числах в китайской классической философии. - М. : Наука, 1993.

[6] Линней К. Философия ботаники. - М. : Наука, 1989.

[7] Люйщи Чуньцю (Весны и осени господина Люя).-М.: Мысль, 2010.

[8] Малявин В.В. Мудрость «безумных речей» // Чжуан-цзы. Лецзы. - М. : Мысль, 1995. - С. 3-56.

[9] Путь золота и киновари: Даосские практики в исследованиях и переводах Е.А. Торчинова. - СПб. : Азбука-классика; Петербургское Востоковедение, 2007.

[10] Уайтхед А.Н. Избранные работы по философии. - М. : Прогресс, 1990.

[11] Чжуан-изы. Ле-цзы. - М. : Мысль, 1995.

[12] Фуко М. Слова и вещи. Археология гуманитарных наук. - СПб. : A-Cad, 1994.

[13] Щуцкий Ю.К. Классическая китайская «Книга Перемен». - Ростов н/Д: Феникс, 1998.

Надійшла до редакчіï 27 березня 2013 р. 